\title{
奈艮縣下葛川産のコバルト鑛物に就いて(第一報) 混合比色法に依る鐵、コバルトの微量分析法
}

(昭和十七知十二月四日受解)

四中信行

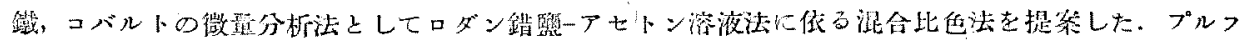

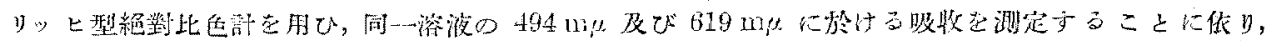

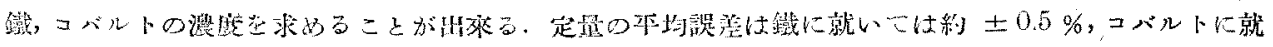

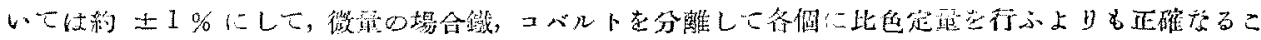

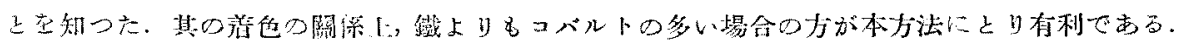

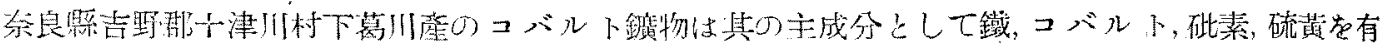

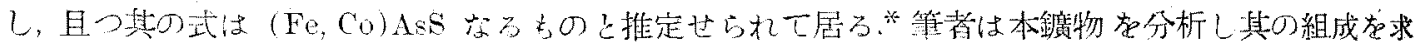

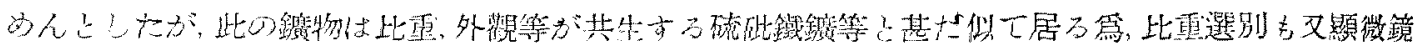

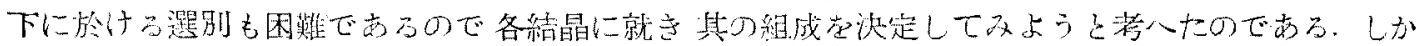

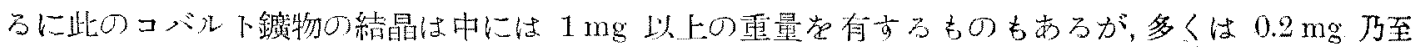

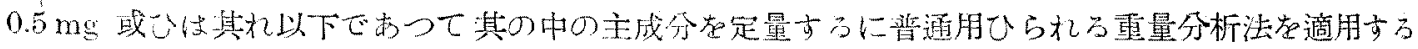

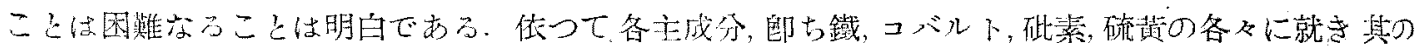

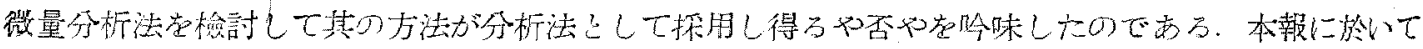
ば其の中鐵、コバルトの分析法に就いてのみ報告する。

$1 \mathrm{mg} \sim 2 \mathrm{mg}$ 或ひは其れ以下の試料就き鐵及びコバル下在重量法に侐り分析することは到底不 可能に近小，又此の 2 元素劣分離して各個に比出定量すること各，分離の際の損失が大となる心配が

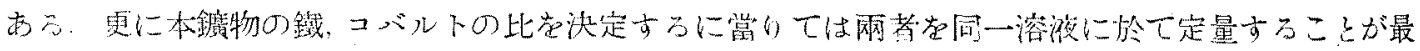

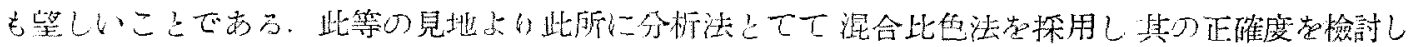
たのでする.

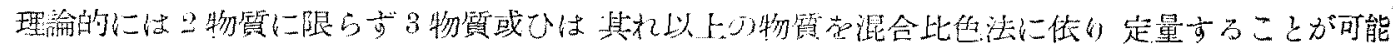

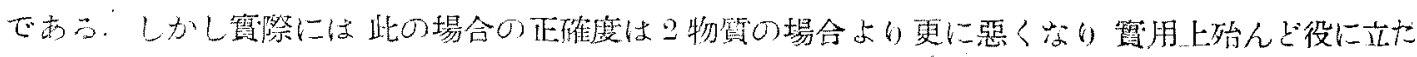

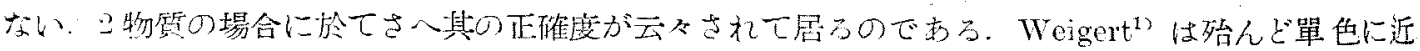

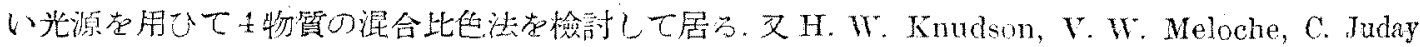

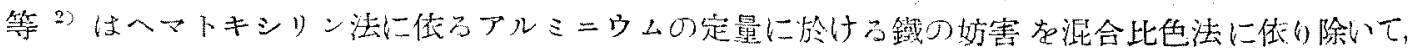

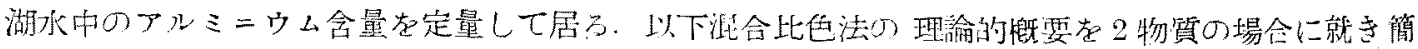
單に記古:

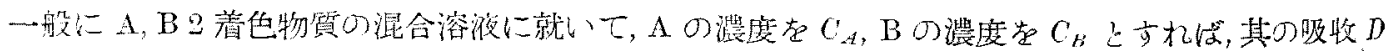

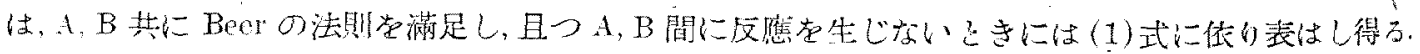

$$
k_{d}\left(l_{x}+k_{B} C_{t}=-=D\right.
$$

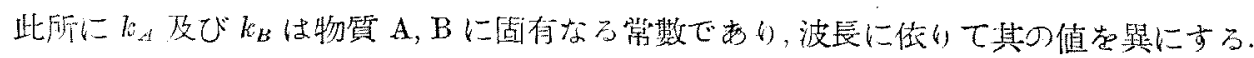

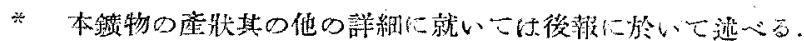

1) F. Weigert: Ber., 49(1916), 1496.

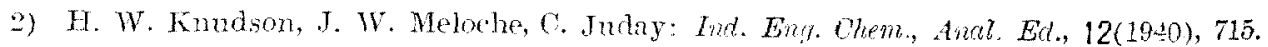


今 $\mathrm{A}$ 物質が最大吸收在示す波長

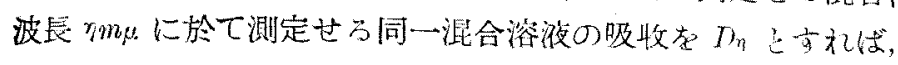

が成立し, 從つて式 (2) 及び(3)より

$$
\begin{aligned}
& k_{A \xi} C_{A}+k_{B} \mathrm{C}_{B}=D_{\xi} \\
& k_{A} \mathrm{O}_{A}+k_{B_{B} \mathrm{C}_{B}}=D_{\eta}
\end{aligned}
$$

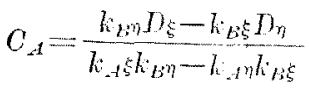

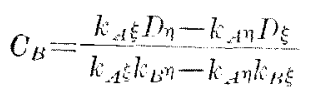

故に豫め純粹なるAに就いて $k_{A \xi}$ 及び $k_{A \eta}$ 在, 純粹なるB

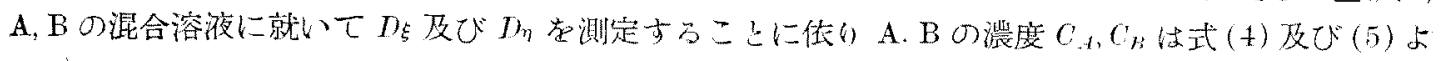

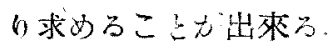

\section{實 驗 の 部}

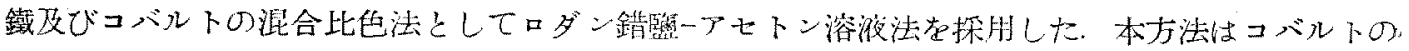

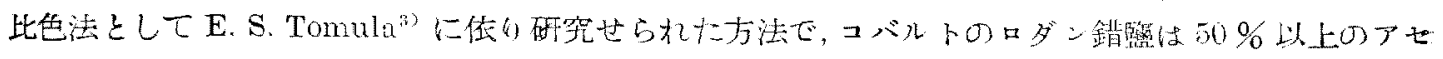
トシ溶液中になては青色学し，其の最 大吸收の波長は $600 \mathrm{~m}$ 一方鐵のロダン錯監は $50 \%$ 以上のアセ トン溶腹中に於ても承溶漼に於けると近 似せる赤色学示し，其の最大吸收の波長 ば 500 mッの附近にある: プルフリッヒ 型絕對比色計に依つて求めたる吸收曲線 は第1圆 a,bの如くである，故に定量に 際して波長 619 m乡 及び $494 m \%$ のィ 几夕一老使用した。

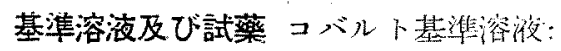
Merk 製分析用の籃化コバルト $\left(\mathrm{CoCl}_{2}\right.$. $\left.6 \mathrm{H}_{0} 0\right)$ th $\alpha-=$ トロソー

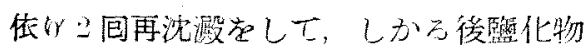
溶澓さした.コバル下の浱度は $\alpha$ ニトロ ソーラーナフトール法依つて定量して決 定した. 本基潅溶滩 $1 \mathrm{cc}$ 中のコバルトの 湝度は0 $0.316 \mathrm{mgCo}$ である。使用に際 しては此狆㾟 10 倍に一稀釋し $31.6 \% \mathrm{Co} / \mathrm{ce}$ とした。

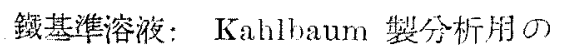

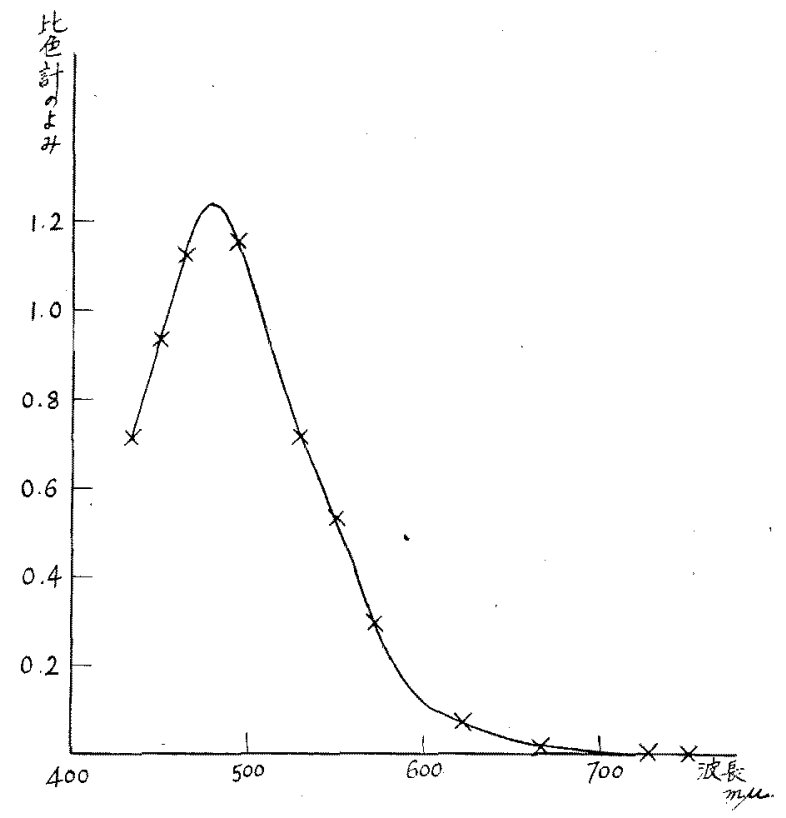

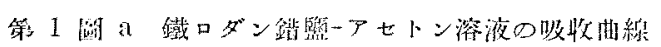

$$
\begin{aligned}
& \mathrm{Fo}+++4.55 \mathrm{~J} \cdot \mathrm{J} \cdot \mathrm{ml}, \quad \text { 口ダンアンモン } 2 \% \\
& \text { アヒトン } 00 \% \text { ，朢酸 } 0.1 \mathrm{~N}
\end{aligned}
$$

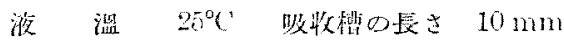

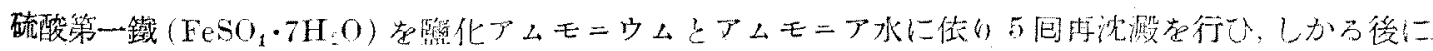

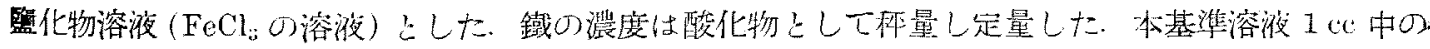

3) E. S. Tomula: Arto Chem. Femba, 2(1929), 72-80; \% anal. Chen., 83(1931), 6-14; F. D. Snell, C. T. Snell: "Colorimetric Methods of Analywis", Vol. I, p. 327, New Yurk (1936). 


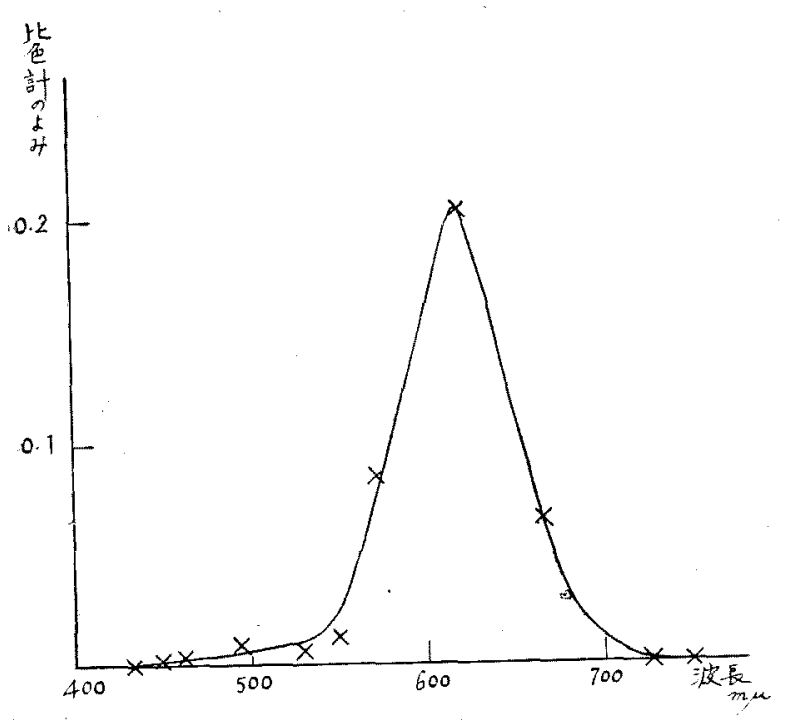

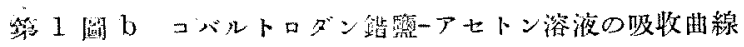

$$
\begin{aligned}
& \mathrm{Co+}+6.32 \mathrm{p} \cdot \mathrm{p} \cdot \mathrm{m}, \quad \text { 口ダンアンモン } 2 \% \\
& \text { アヒトン } 50 \% \text {, 整 酸 } 0.1 \mathrm{~N}
\end{aligned}
$$

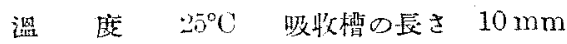

鐵 $\left(\mathrm{Fe}^{+++}\right)$の濃度は $4.55 \mathrm{mg} \mathrm{Fe}$ である。 使用に際しては此れを 100 倍に稀釋して $45.5 \gamma \mathrm{Fe} / \mathrm{ce} と し た$.

ロダン試藥： $20 \%$ ロダンアムモン溶 滩.

アセトン及じ其の他藥品の何れも鐵更 びコバルトを含有して居ないことを確認 して使用した。

定量操作 試料在 $2 \sim 3 \mathrm{cc}$ の水溶㖡

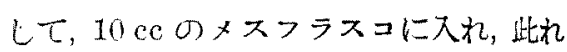
にロダン試燕 $1 \mathrm{cc}$ 在加へ, 更にアセトン $5 \mathrm{cc}$ 觉加一て後, 蒸溜水にて全淮量在 10

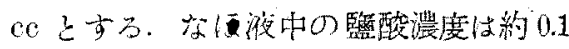
Nにす万．此の操作に依つて液溫がや、 上昇する故流水にて冷却して液溫在 $25^{\circ} \mathrm{C}$

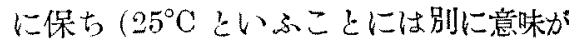
标い.8月に此の實驗觉行つたので流水 の溫度が $25^{\circ} \mathrm{C}$ 位であつた.), 10 分後に ルフリッ七型絕對比色計にて $619 \mathrm{~m} \mu$ 及

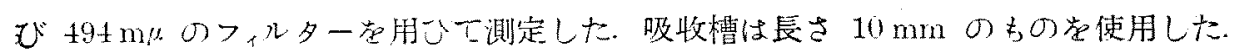

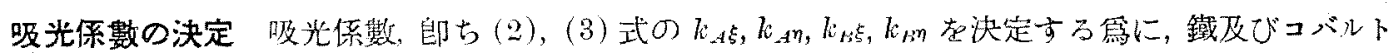

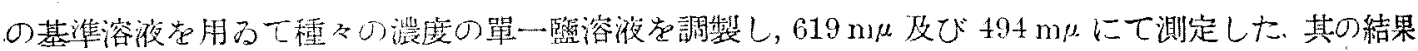

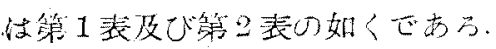

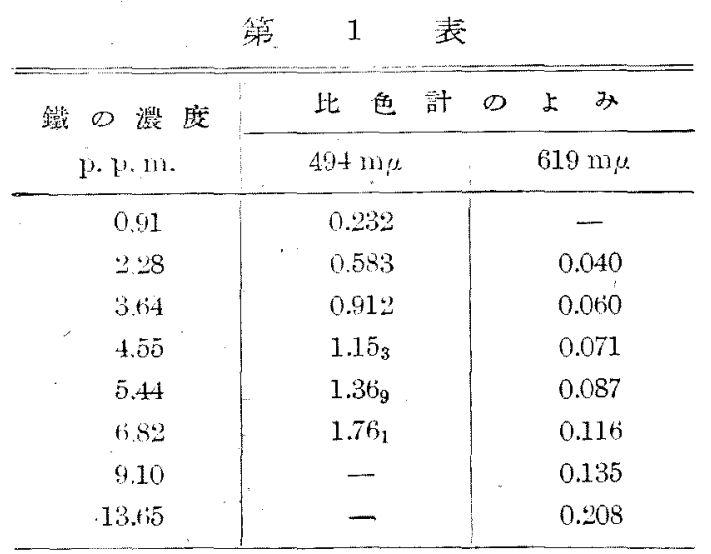

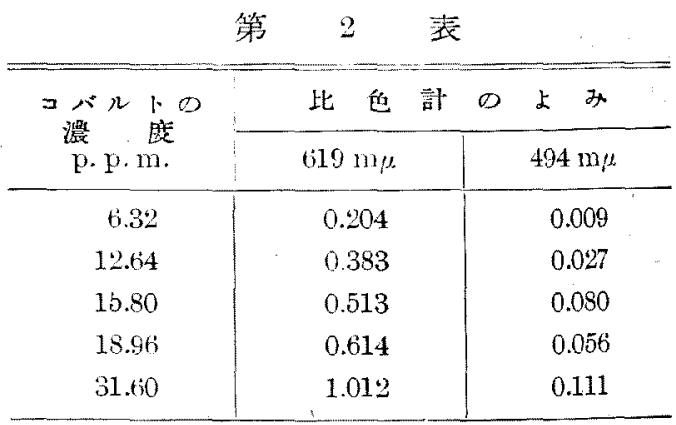

又此れ学圆示したのお第 2 圖 $\mathrm{a}, \mathrm{b}$ である。

第口圆 a, b に見乃如く、鐵及びコバットの何れ の)場合も，Beer の法則存滿足する．從つて淈合溶

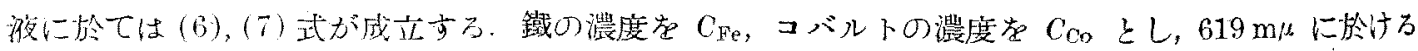

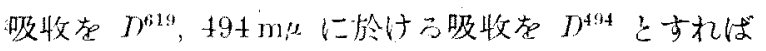

$$
\begin{aligned}
& k_{\mathrm{Fe}}^{619} C_{\mathrm{Fe}}+k_{\mathrm{Co}}^{\mathrm{619}} C_{\mathrm{Co}}=7^{619} \\
& k_{\mathrm{Fe}}^{494} C_{\mathrm{F}}+k_{\mathrm{Co}}^{494} C_{\mathrm{Co}_{0}}=I^{494}
\end{aligned}
$$

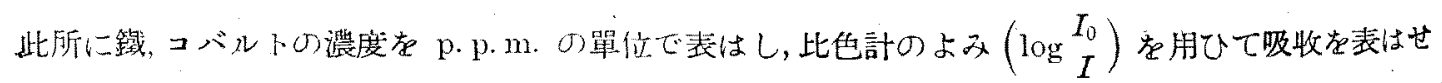




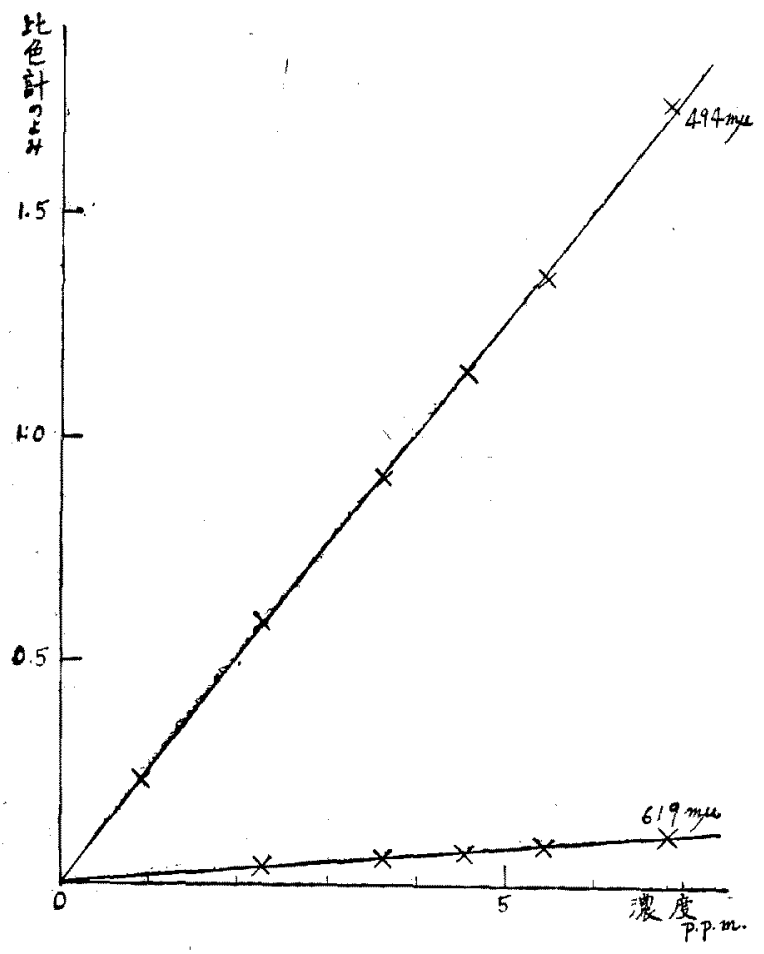

第 2 圖 a $\mathrm{Fe}^{+++}$の辳度と吸收との關保

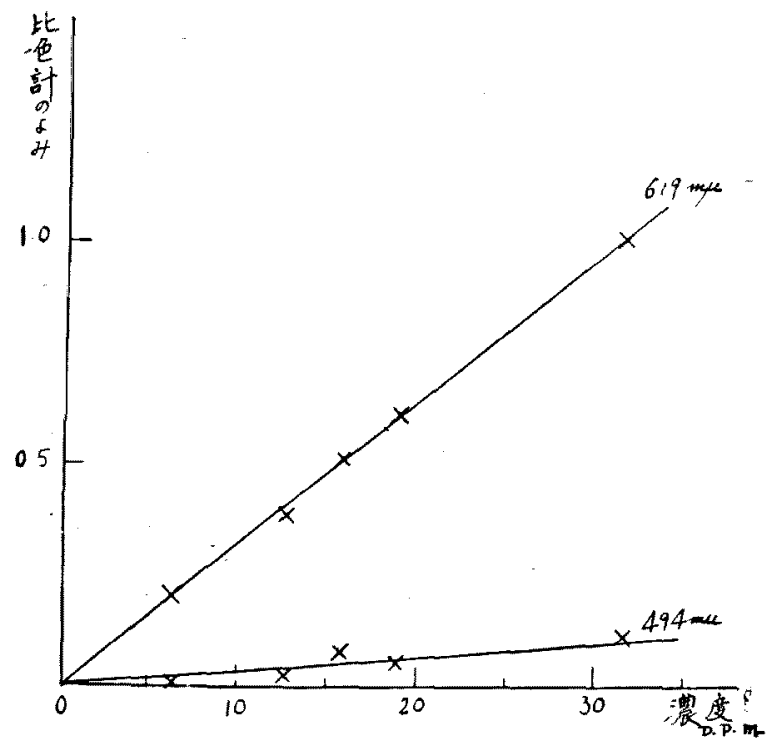

第 2 涌 $\mathrm{b} \mathrm{Co}^{++}$の溜度々吸收々の關係

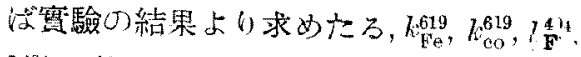
$k_{\mathrm{Co}}^{494}$ の值は次の如くである。

$$
\begin{array}{ll}
k_{\mathrm{F}}^{619}=0.0160 & k_{\mathrm{CO}}^{619}=0.0320 \\
k_{\mathrm{Fe}}^{494}=0.254 & k_{\mathrm{Co}}^{494}=0.0029
\end{array}
$$

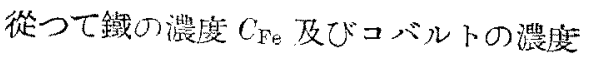
$C_{\mathrm{Co}}$ は泥合溶液の619 m\% 及び $494 \mathrm{m \mu k}$ 於け万吸收虎测定することに低り式 (8) 及び (9) 上い求めら机ら。

$$
\begin{aligned}
& C_{\mathrm{Fe}}=\frac{0.0320 D^{404}-0.0029 D^{61 !}}{0.00808} \\
& \text { (p.p.m.) } \\
& C_{\mathrm{Co}}=\frac{0.25 \pm D^{6 \mathrm{jy}}-0.0160 D^{4: 4}}{0.00808} \\
& \text { (p.p.n.) }
\end{aligned}
$$

方法の檢討 朴方法の正確度を檢討与

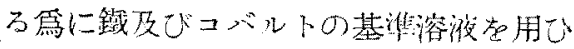
種々の摆度の泿合溶液老調製し，上記の 方法にて定星した。其の結果は第 3 表の 如くである。之上り分る如く本力法の最 大誤差は約 $2.5 \%$ にして平均誤差は土

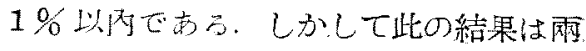
者学分離して各個に比出定量行ふ上り も優れて居る様に思仕れ，殊兩者の比 龙的己に當的ては，此色定量に於け万 直接誤差以外に何等方解差灰含まない點 に於いて他の方法方追從部さないし考。 $\sim 3$.

しかし吸光係數にても分る如く， $k_{\mathrm{Fe}}^{494}$ と $k_{\mathrm{Co}}^{494}$ の值には甚だ差があるに對して， $k_{\mathrm{Co}}^{619 *}$ と $k_{\mathrm{Fe}}^{\mathrm{Oly}}$ に就いては前者が後者の2倍に過 ぎない，從つて定量の韶差もコバルトの，

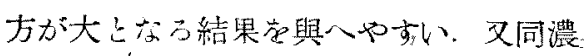
度の鐵，コバルトの最大吸收は前者が後 者心約て倍なつ故, 鐵がコバルトに比し て少极き場会が其の逆の場合に比し本定。 量法によりて有利である。

共存イオン, 溫度, $\mathbf{p H}$ 等の影響 共存イオンとしては存在の可能性のあるものの中, ニッヶルは多.

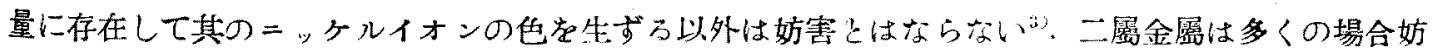

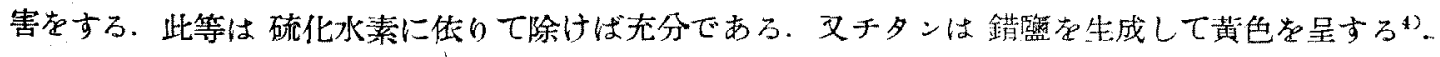

4) F. D. Snell, C. T. Snell: "Colorimetric Methods of Analysis", Vol. I, p. 283-298, New York (1936). 


\begin{tabular}{|c|c|c|c|c|c|c|c|c|c|}
\hline \multirow{3}{*}{$\frac{\mathrm{I} ! !}{\mathrm{Co}}$} & \multirow{3}{*}{ 值 } & \multirow{2}{*}{\multicolumn{2}{|c|}{ 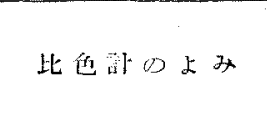 }} & \multirow{2}{*}{\multicolumn{2}{|c|}{$\begin{array}{r}\text { 题 } \\
(\gamma)\end{array}$}} & \multicolumn{2}{|c|}{ 鿒是 } & \multicolumn{2}{|c|}{ 坡 } \\
\hline & & & & & & \multicolumn{2}{|c|}{$\mathrm{Co}$} & \multicolumn{2}{|c|}{$\mathrm{Fe}$} \\
\hline & & $61911 \%$ & $494 \mathrm{~m} \%$ & $\mathrm{Co}$ & $\mathrm{Fe}$ & $\gamma$ & $\%$ & $\gamma$ & $\%$ \\
\hline 32.6 & 20.8 & 0.142 & 0.586 & 33.0 & 22.7 & +0.4 & +1.2 & -. 0.1 & -0.4 \\
\hline 49.4 & 44.2 & 0.233 & $1.14_{t}$ & 50.7 & 443 & +1.3 & +2.6 & +0.1 & +0.2 \\
\hline 97.8 & 44.5 & 0.382 & $1.15_{9}$ & 97.4 & 44.5 & -0.4 & -0.4 & 0.0 & 0.0 \\
\hline 97.8 & 18.2 & 0.420 & $1.74_{3}$ & 97.4 & $\$ 7.7$ & -0.4 & -0.4 & -0.5 & -0.7 \\
\hline 130.4 & $4 \overline{0} . \overline{0}$ & 0.489 & $1.21_{0}$ & 129.7 & 46.2 & -0.7 & -0.5 & +0.7 & +14 \\
\hline 163.0 & 45.5 & 0.592 & $1.20_{7}$ & 164.0 & 45.7 & +1.0 & +0.6 & +0.2 & +0.4 \\
\hline
\end{tabular}

其れ以外はイオンの色しして塎液に着色落與八ない程度なら妨害しはならない㥞である。

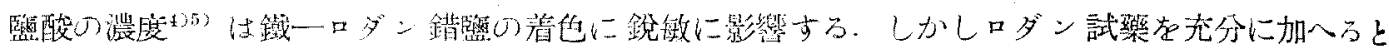

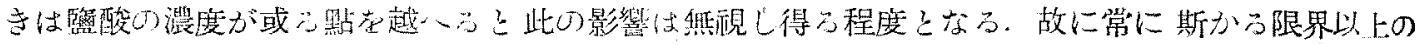

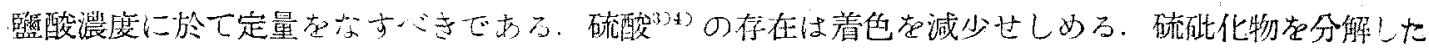

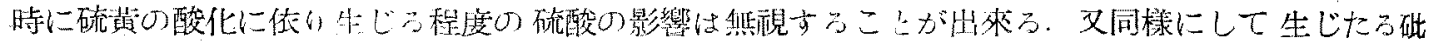

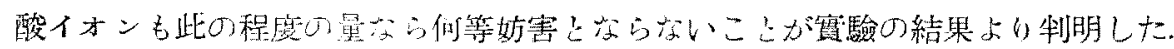

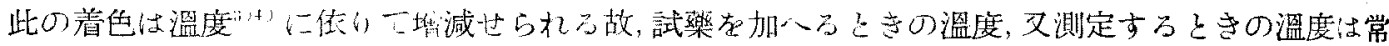

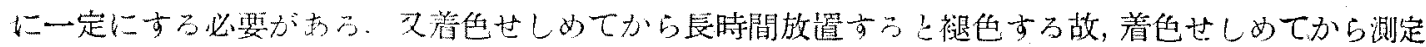

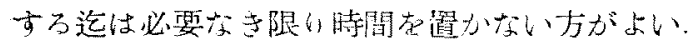

以上の結果より本方法はコバル下鑛物中の鐵，コバルトの微量分析法しして充分に採用し得るもの 々考心る.

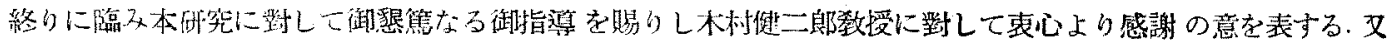

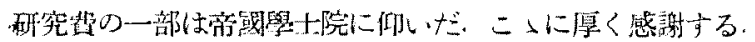

(果京帝國大學理學部化學数宝)

5) 奥野：本誌，62(昭和 16$), 1158$. 